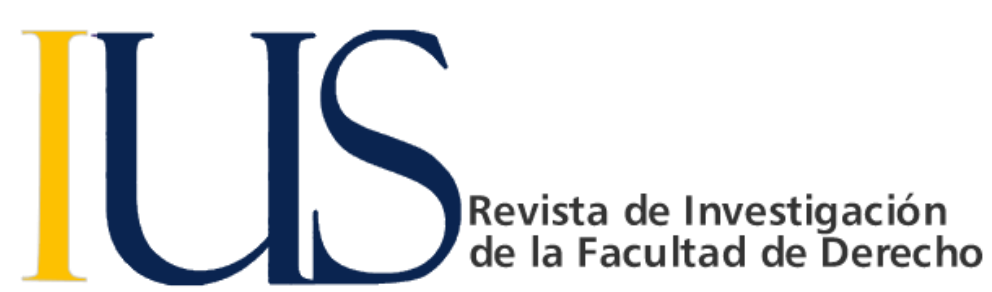

\title{
APUNTES DE HISTORIA DEL DERECHO PERUANO. CRISTÓBAL VACA DE CASTRO, GOBERNADOR DE LA NUEVA CASTILLA (1541-1543)
}

\section{Freddy Ronald Centurión González ${ }^{1}$}

\begin{tabular}{|c|c|}
\hline INFORMACIÓN DEL ARTÍCULO & RESUMEN \\
\hline \multirow[t]{4}{*}{$\begin{array}{l}\text { Historia del artículo: } \\
\text { Recibido el } 20 \text { de junio de } 2019 \\
\text { Aceptado el } 02 \text { de agosto de } 2019\end{array}$} & \multirow{2}{*}{$\begin{array}{l}\text { La Gobernación de Nueva Castilla, que existió entre } 1529 \text { y 1542, hasta la } \\
\text { creación del Virreinato del Perú, estuvo bajo el poder sucesivo y accidentado } \\
\text { de dos gobernadores: el Marqués Francisco Pizarro y el Licenciado Cristóbal } \\
\text { Vaca de Castro. El breve gobierno de este último, signado por las guerras civiles } \\
\text { entre los conquistadores, fue no obstante, importante en el fortalecimiento de } \\
\text { la autoridad metropolitana, aunque también, quedó manchado por serias } \\
\text { acusaciones de corrupción }\end{array}$} \\
\hline & \\
\hline & $\begin{array}{l}\text { Notes of history of peruvian law. Cristóbal Vaca de Castro, governor of the New } \\
\text { Castle (1541-1543) }\end{array}$ \\
\hline & ABSTRACT \\
\hline $\begin{array}{l}\text { Keywords: } \\
\text { History } \\
\text { viceroyalty of Peru } \\
\text { colonial period }\end{array}$ & $\begin{array}{l}\text { The Government of New Castile, which existed between } 1529 \text { and } 1542 \text {, until } \\
\text { the creation of the Viceroyalty of Peru, was under the successive and troubled } \\
\text { power of two governors: the Marquis Francisco Pizarro and the Licenciado } \\
\text { Cristóbal Vaca de Castro. The brief government of the latter, the sign of civil } \\
\text { wars among the conquerors, was not, however, the importance of } \\
\text { metropolitan authority, but also, was stained by serious accusations of } \\
\text { corruption }\end{array}$ \\
\hline
\end{tabular}

\section{Introducción}

La Gobernación de Nueva Castilla, como ente territorial, duró apenas algo más de una década: entre 1529, en que se firmó la Capitulación de Toledo entre la Corona y Francisco Pizarro, hasta 1542, en que las Leyes Nuevas crearon el Virreinato del Perú. Ese lapso bastó para asegurar el establecimiento de la autoridad hispánica en territorio andino, y estuvo dominado en su mayor etapa por la figura del Marqués Gobernador, ocupado en la fundación de ciudades y en las guerras, primero contra los indígenas y luego contra los partidarios de su antiguo socio, el Adelantado Diego de Almagro.

Sin embargo, no fue Francisco Pizarro el único Gobernador que la Corona designó para los reinos del Perú. En medio del torbellino de las guerras civiles, la preponderancia que adquirió el Marqués en el territorio peruano, no dejó de inquietar a la Corona, la cual buscó limitar sus amplios poderes (Centurión, 2016). Para fiscalizar a Pizarro, se envió desde España a un funcionario con amplias atribuciones, el Licenciado Cristóbal Vaca de Castro, quien llegaría a ser el segundo

\footnotetext{
1 Egresado de la Maestría en Derecho Constitucional y Gobernabilidad de la Universidad Nacional Pedro Ruiz Gallo, Docente de Derecho Constitucional e Historia del Derecho en la Facultad de Derecho de la USAT, Chiclayo, Perú. Contacto: fecnturión@usat.edu.pe ORCID: https://orcid.org/0000-0002-1977-37362
} 
y último Gobernador de la Nueva Castilla, antes de la creación del Virreinato del Perú.

El fin de Francisco Pizarro cerró el período de la invasión y conquista del Perú y dio paso a una época de convulsiones, en la que se harían explícitas las formas de violencia latentes en el grupo colonizador, Era natural que la corona procediese con Pizarro de igual manera como lo había hecho con sus predecesores en otras regiones americanas desde las épocas de Colón y recuperase la autoridad política que había delegado al conquistador. Pero, en el Perú, el conflicto entre Pizarro y Almagro, con su desenlace sangriento, precipitó que el grupo encomendero inicial perdiese el poder, que sería recuperado por los representantes del estado imperial. Este momento coincidió con la presencia del licenciado Cristóbal Vaca de Castro, cuyas Instrucciones de gobierno se fundamentaban en los "muchos malos tratamientos" que se hacían a los indios, pero también enfatizaban la necesidad de efectuar "la tasación de los yndios que están encomendados al dicho marqués [Pizarro] y a sus hermanos, parientes, criados y familiares. En una suerte de premonición fatídica de los hechos, las autoridades metropolitanas habían investido a Vaca de Castro con la autoridad necesaria para la misión que le tocaría cumplir (Varón, 1996, p. 129).

La figura de Vaca de Castro suele ser poco estudiada, dada la fugaz duración de su cargo. Se suele revisar su figura en medio de las guerras civiles como un mero agente de la Corona, que liquidó de forma sangrienta a la facción almagrista, o como un funcionario ambicioso en aras de acumular una fortuna en las Indias. Creemos necesario acercarse a su labor de gobierno en aras de completar la investigación anterior sobre la labor del Marqués Francisco Pizarro, primer gobernador de la Nueva Castilla, y de conocer, en base a los medios disponibles, la situación legislativa del territorio peruano al momento del establecimiento del Virreinato.

\section{EL LICENCIADO VACA DE CASTRO}

Según las informaciones tomadas en León y Mayorga para otorgarle el hábito de Santiago, don Cristóbal Vaca de Castro, señor de los lugares de Izagre y Santa María del Otero, era hijo de don García Díaz de Cadórniga y de doña Guiomar Cabeza de Vaca, ambos vecinos de Mayorga y señores de los referidos lugares de Izagre y Santa María del Otero (García, 1957, pp. 13-15).

Es poco lo que se sabe de Vaca de Castro antes de su nombramiento como Juez Pesquisidor en 1540. Se sospecha que pudo haber estudiado leyes en Salamanca, donde debió aprender las normas del ius commune en boga en la época. Dada su edad, creemos imposible que haya escuchado las lecciones de Francisco de Vitoria, quien obtuvo la cátedra en Salamanca en 1526. Una carta citada por el padre Cappa, a quien cita Vargas Ugarte (1981), menciona que Vaca de Castro fue criado del cardenal García de Loaysa, arzobispo de Sevilla, siendo su alcalde mayor y juez en Siguenza. Sin embargo, se sabe con certeza que era casado con doña María Magdalena de Quiñones y Osorio con quien tuvo ocho hijos. Para 1534 era corregidor de la villa de Roa, donde nació su hijo Pedro de Castro y Quiñones, futuro arzobispo de Granada.

En 1536, por traslado del oidor Cristóbal de Aldrete al Consejo Real (Jiménez de la Espada, 1877), Vaca de Castro pasó a ocupar el puesto que resultaba vacante en la Real Audiencia y Chancillería de Valladolid, ciudad en la que establecería su residencia. Dicho tribunal era uno de los más importantes en el reino de Castilla, de forma que bajo su jurisdicción se encontraba el territorio situado al norte del río Tajo (Varona, 1981). Por entonces, se le otorgó permiso de hacer las informaciones correspondientes para obtener el hábito de Santiago en León, en Mayorga y en Valladolid (30 de diciembre de 1539).

\subsection{La misión de vaca de castro}

Se encontraba el Licenciado Vaca de Castro asentado en Valladolid cumpliendo sus deberes de oidor, cuando llegaron a la Península noticias sobre los alborotos acontecidos en las tierras del Perú, el alzamiento de los indígenas encabezados por Manco Inca, la guerra civil entre los partidarios del Gobernador Francisco Pizarro y del Adelantado Diego de Almagro, concluida con sangre en la batalla de las Salinas y rematada con la ejecución de Almagro por disposición de Hernando Pizarro. La vehemencia de los partidarios del difunto Adelantado en la Corte exigiendo el castigo para los Pizarro, y las sospechas ante la preponderancia que el Gobernador Pizarro adquirió en las tierras peruanas, hicieron necesario el envío de un delegado y juez capaz de dilucidar la mejor solución a los problemas peruleros.

El estado de desórden en que se hallaba el Perú era tal que exigía la inmediata intervención del gobierno. Entre la general licencia que predominaba, los derechos del indio y los del español eran igualmente hollados. El asunto, sin embargo, ofrecía grandes dificultades; porque la autoridad de Pizarro se hallaba firmemente establecida en el país, y este demasiado lejos de Castilla para ser fácilmente vigilado desde la metrópoli. Pizarro además era hombre de no fácil acceso, seguro de su propia fuerza, incapaz de sufrir intervención alguna, y dotado de un carácter irritable, que se inflamaría á la menor señal de desconfianza de parte del gobierno. No convenía enviar una comisión para suspenderle del 
ejercicio de su autoridad hasta investigar su conducta, corno se había hecho con Cortés y con otros grandes capitanes de América, en cuya arraigada lealtad confiaba enteramente la corona. Era de temer que la lealtad de Pizarro no tuviese las raíces suficientes para resistir los primeros movimientos de su impetuoso carácter; y no le faltaba gente turbulenta, que en caso extremo le habría aconsejado que se desentendiese de toda obligación á la corona y fundase para sí un gobierno independiente (Prescott, 1851, p. 162).

Las opiniones sobre lo que habría de hacerse en el Perú eran diversas. El cardenal García de Loaysa y Mendoza, arzobispo de Sevilla y expresidente del Consejo de Indias, con alta influencia en la Corte, de común acuerdo con el secretario real Francisco de los Cobos y el conde de Osorno, don García Fernández Manrique, presidente en funciones del Consejo de Indias, resolvieron en la necesidad de enviar a una persona al Perú (Varón, 1996). Al final, se decidió enviar al más temible de los enemigos que podía contemplar un Gobernador de Indias: un juez de residencia.

Los comisionados reales o jueces de residencia eran la pesadilla de los gobernadores. Significaban en realidad el ocaso de su estrella y el término de su poderío. En todas partes de América los jueces de residencia depusieron a los jefes de Gobierno y a algunos los mandaron con grillos a España (Porras, 1978, p. 589).

A sugerencia del cardenal Loaysa, con quien Vaca de Castro habría tenido buenas relaciones, se propuso la designación del Licenciado leonés como "persona de integridad, graue, yapta para grandes negocios" (Herrera, 1615a, p. 237). Sin embargo, de la lectura de dos cartas del cardenal Loaysa a Vaca de Castro, una del 27 de agosto de 1540 y otra del 19 de septiembre siguiente, se podría deducir que el Licenciado tenía ciertas dudas en viajar a las Indias, por lo que el purpurado no dudó en mencionar los asuntos de dinero y la posibilidad de un ascenso en su carrera en la magistratura, a fin de lograr su aceptación, insistiéndole en la necesidad de actuar de común acuerdo con el Marqués Gobernador, al que elogiaba como "bendito ombre" (Porras, 1959, p. 386). No obstante, pese a la urgencia de la situación se insistió en retrasar el viaje de Vaca de Castro hasta recibir los datos que pudiese aportar Hernando Pizarro, a fin de que contase con una clara visión de los hechos y con instrucciones precisas (Varón, 1996). Hernando llegó en efecto, y su presencia fue mal vista por muchos, y aunque se defendió judicialmente de los ataques de los almagristas y del fiscal Villalobos, terminó por purgar una prisión de veintiún años por la muerte de Almagro; incluso escribió en contra del nombramiento de Vaca de Castro, pero no se le prestó atención (Porras, 1959).

\subsubsection{Las Instrucciones del Emperador}

Habiendo entendido las alteraciones y cosas acaecidas en nuestro Reyno de Nueva Castilla, que es en la Provincia del Perú, para ser informados de la verdad de lo que en ésta ha pasado, y hacer justicia a las partes que la pidieren; y así mismo para saber el recaudo y fidelidad que ha habido en nuestra hacienda y patrimonio Real, cómo se han guardado y cumplido nuestras provisiones que a la dicha Provincia habemos mandado, enviar, así tocante a la instrucción y conversión y buen tratamiento de los naturales de ella, como para la perpetuidad y noblecimiento y población de las dichas provincias (García, 1957, p. 20).

Con tal texto, iniciaban las instrucciones entregadas a Vaca de Castro el 15 de junio de 1540. El pliego de instrucciones fue largo y prolijo, dado que se quería remediar con su viaje, una serie de problemas y abusos que se habían introducido en la administración indiana. Sin embargo, lejos de ser un texto único, las instrucciones fueron modificadas, ampliadas o reducidas en una serie de tira y afloja buscando evitar ofender al Marqués Gobernador, dando por resultado que Vaca de Castro contase con poderes discrecionales que podría interpretar a su libre albedrío, lo que se fortaleció aún más con la Cédula de 9 de septiembre de 1540, que le otorgaba el nombramiento de Gobernador en reemplazo del viejo Marqués, únicamente en caso de muerte u otro accidente extraordinario. Esto fue justificado por la edad de Pizarro, aproximadamente sesenta y dos años en 1540, edad juzgada avanzada en el siglo XVI.

Dado el breve espacio con que contamos, y a fin de una mejor comprensión, usaremos las fuentes que tenemos a la mano para compendiar las instrucciones que se le entregó a Vaca de Castro: el cronista Herrera (1615a), el erudito Jiménez de la Espada (1877), el general Mendiburu (1890), el padre García (1959) y el maestro Porras (1978).

1. Ante las noticias de los abusos de los que eran victima los indígenas en aras de conseguir oro y plata, y enviarlos a trabajos contra su voluntad, y el poco cumplimiento de las disposiciones dadas por la Corona, se encargó a Vaca de Castro que buscase castigar lo pasado y remediar para el futuro.

2. Vaca de Castro debía averiguar los hechos de la guerra entre Pizarro y Almagro, y los excesos cometidos antes y después de la batalla de Las Salinas, a fin de informar a la Corona con exactitud de lo acontecido. Teniendo en cuenta que la diferencia limítrofe fue la causa del conflicto entre Pizarro y Almagro, la Corona 
encargó a Vaca de Castro averiguar con certeza los límites de las gobernaciones de Nueva Castilla y de Nueva Toledo.

3. Dada la exigencia de tributos elevados por parte de ciertos encomenderos, Vaca de Castro debía cooperar con el Marqués Gobernador y el obispo del Cuzco, en el cumplimiento de las órdenes reales dadas por carta del Emperador en diciembre de 1537, a fin de establecer la tasa definitiva del tributo indígena. Además, el comisionado debía velar que los repartimientos se hiciesen con justicia.

4. Dado el interés de la Corona en la evangelización, se decidió crear dos nuevos obispados, uno en Lima y el otro en Quito; en tal sentido, Vaca de Castro se encargaría de delimitar la jurisdicción de cada obispado, para lo cual, debía emprender una visita del territorio peruano.

5. Vaca de Castro debía también, verificar el cumplimiento de las disposiciones reales enviadas con anterioridad al Gobernador Pizarro, al obispo Valverde y a los Oficiales Reales; en caso de incumplimiento, hacer que las disposiciones reales se cumpliesen de la forma debida. Además, el comisionado regio debía estudiar las necesidades del país a fin de informar a la Corona las medidas necesarias para tales asuntos.

6. Ante las denuncias del mal funcionamiento de las cuentas de la Real Hacienda, el comisionado regio debía verificar su real situación, cobrar los retrasos existentes, y sancionar a los Oficiales Reales en caso de mal uso de sus funciones. También debía examinar la forma del cobro de tributo y el adecuado reparto de los tesoros, asegurándose del oportuno envío de los fondos pertenecientes a la Corona.

7. Considerando que la Corona tenía el máximo interés en la idea evangelizadora, Vaca de Castro tenía la misión de fundar monasterios en los lugares más convenientes, informándose del uso de los diezmos y de la conducta de los religiosos, a fin de expulsar a los que mostrasen conductas escandalosas. También se debía asegurar horas a los indígenas para acudir a la iglesia para ser instruidos en temas de la fe; los antiguos templos indígenas debían ser consagrados como templos cristianos.

8. La Corona, preocupada por la situación de los indígenas, encargó a Vaca de Castro que impidiese el traslado de indios de unas provincias a otras, para evitar los problemas surgidos por el cambio de clima; que se prohibiese la carga de pesos excesivos en los porteadores indios que contraviniesen las ordenanzas respectivas; que se informase y corrigiese los despojos de tierra a los indios principales; que negociase con Manco Inca su entrega y la concesión de tierras, siendo deseable su envío a España para evitar inconvenientes en el Perú; también tendría que efectuar una lista de los hijos de Huayna Cápac para que recibieran atenciones de la Corona.

9. Ya que Vaca de Castro se hallaría en camino al Perú, a su paso debía visitar Puerto Rico y Santo Domingo a fin de informar sus condiciones a la Corona; además indagaría la situación en la Audiencia de Panamá, dadas las quejas sobre la actuación del oidor decano, doctor Francisco Pérez de Robles, iniciando juicio de residencia a sus oidores.

Si bien Vaca de Castro no contaba con una mayor autoridad que la del Marqués Gobernador, la Corona juzgó necesario realzar su persona para el mejor cumplimiento de su comisión. Por ello, se designó a Vaca de Castro miembro del Consejo de Castilla, además de concederle un hábito de Santiago, una de las órdenes militares más ilustres de la Monarquía Hispánica. Incluso el Emperador le prometió que, en caso de fallecimiento en su comisión, se otorgaría doscientos ducados de renta a su esposa, además de mercedes y gratificaciones a sus hijos (Herrera, 1615a).

\subsubsection{El largo viaje al Perú}

Habiendo hecho los trámites pertinentes, Vaca de Castro embarcó hacia las Indias en Sanlúcar de Barrameda a principios de noviembre de 1540. Tras una escala en la isla de la Gomera, siguió viaje, perturbado por tormentas y vendavales que le impidieron llegar a Puerto Rico, por lo que enrumbó a Santo Domingo, donde visitó la fortaleza. Allí, recabó la información necesaria sobre la situación en Puerto Rico, por lo que no vio necesidad en viajar a dicho punto. Pasó después a Nombre de Dios, cruzó el istmo, hasta llegar a fines de febrero de 1541, a Panamá.

Conforme sus instrucciones, Vaca de Castro asumió la Presidencia de la Audiencia de Panamá, suspendió al oidor Robles, e inició el juicio de residencia a sus colegas oidores, doctor Pedro de Villalobos y licenciado Lorenzo Paz de la Serna. Recién el 19 de marzo, el comisionado regio emprendió viaje hacia el Perú, en una pésima estación, y tras un pésimo viaje, anclaron en el puerto de Buenaventura. Como el navío quedó en lamentables circunstancias, el Licenciado leonés optó por seguir a Cali, y de allí, por tierra continuar viaje al Perú. Para colmo de males, Vaca de Castro enfermó: Cieza (1994a) apunta que "a no estar en su conpañia un médico e çirujanos, muriera" (p. 149), por lo que terminó convaleciendo en Cali, con riesgo de muerte, durante tres meses. Pese a sus dolencias, Vaca de Castro ordenó 
al Adelantado Sebastián de Belalcázar liberar al Adelantado Pascual de Andagoya, convocándolos a su encuentro, a fin de solucionar sus diferencias sobre la gobernación del Río de San Juan. No resolvió nada en dicha cuestión, ya que decidió remitir la documentación al Consejo de Indias para que tomasen la mejor decisión; Andagoya viajó a la península para defender sus derechos, en tanto que Belalcázar se quedó, ordenando a sus tenientes proveer los caminos para el viaje que Vaca de Castro emprendería a Popayán, con la intención de continuar viaje al Perú. Era ya agosto de 1541, y la situación en el Perú había cambiado tremendamente.

Mientras Vaca de Castro viajaba hacia el Perú, las noticias sobre una falta de imparcialidad del enviado real no dejaron de adelantársele (Herrera, 1615a). Ello no dejó de exaltar los ánimos de los derrotados almagristas, que incluso quisieron quemar la efigie del cardenal Loaysa. A ello se sumó una serie de rumores, primero sobre la muerte del comisionado en el viaje hacia el Perú por órdenes del Marqués, y luego las sospechas del soborno.

El viejo Marqués Gobernador no dejó tampoco de alarmarse ante la inminente llegada de Vaca de Castro; ya había demostrado una conducta altiva ante fray Tomás de Berlanga, obispo de Panamá y comisionado de la Corona en 1534, y si había algo que le preocupaba enormemente era el porvenir de su gobernación, especialmente dadas las instrucciones del nuevo comisionado. En la última carta que dictó, once días antes de su muerte, un dolido y premonitoriamente lúgubre Pizarro lamentaba los rumores que llegaban sobre la cercana posibilidad de separar Charcas y Arequipa de la Nueva Castilla: "porque sy ansy no se parten estas gobernaçiones su magestad no puede ser servydo y yo quedo governador de arenales" (Porras, 1959, p. 402).

Sin embargo, el viejo extremeño actuó con calma y envió un navío a Panamá para recoger al comisionado regio, que este no aceptó para no dar lugar a sospechas (Mendiburu, 1890). Incluso intentó congraciarse con algunos de los almagristas, pero ya era tarde dado los actos de arbitrariedad cometidos. Los almagristas se fueron concentrando en Lima, en torno de la figura del hijo mestizo de su difunto líder, también llamado Diego de Almagro; los soldados almagristas lo conocían de las campañas que emprendiese su progenitor, y muerto este, trasladaron su adhesión al hijo. Ante los crecientes rumores de una conjura en su contra, Pizarro se entrevistó con Juan de Herrada (o de Rada), tutor del joven Diego de Almagro el Mozo, jefe visible de la facción rival, buscando calmar los ánimos. Fue en vano: sabido es que el domingo 26 de junio de 1541, los almagristas asaltaron la residencia del conquistador, y pese a la desesperada y corajuda defensa, el Marqués Francisco Pizarro, Gobernador de la Nueva Castilla, cayó asesinado.

El defecto capital de la acción del Consejo de Indias y del mismo Vaca de Castro fue su morosidad. La batalla de Las Salinas se realizó en abril de 1538 y sólo en junio de 1540 se provee a Vaca de Castro como juez. En octubre de 1540 todavía está por partir de Sevilla y aún se le dan nuevas comisiones para visitar la fortaleza de Santo Domingo, a la que llega en enero de 1541, y para resolver pleitos de oidores en Panamá. Allí, Vaca de Castro, en vez de embarcarse directamente para el Perú, adopta, por temor, las peores y más complicadas vías de comunicación. Si hubiera viajado directamente para el Perú habría llegado a tiempo para impedir la muerte del Marques y la guerra de Chupas. Pero se embarcó en un navío estropeado y estuvo recalando, por falta de buenos pilotos, entre la Gorgona, la Isla del Gallo y el puerto de Buenaventura, y tuvo hasta el desatino de naufragar. Por último se metió en Buenaventura y a Cali para venir por Popayán y por Quito al Perú, haciendo por tierra un recorrido de seis meses, en lugar de un viaje por mar de trece o catorce días. Entre tanto prendió en el Perú el incendio de la guerra civil (Porras, 1978, pp. 590-591).

\subsection{La guerra de Chupas}

El nuevo Gobernador del Perú, de facto ciertamente, fue Diego de Almagro el Mozo, aunque el poder en la sombra, era su tutor, Juan de Herrada, nombrado Capitán General. Hijo del Adelantado Almagro, el joven Gobernador rondaba los veinte años; era muy parecido a su difunto padre, en el carácter franco y en la violencia de las pasiones. Bajo sus estandartes, se alistaron entre 500 y 800 hombres, la mayor parte españoles vagabundos, precisamente el objetivo de las últimas ordenanzas del difunto Marqués (Centurión, 2016). Valdría la pena dedicar en algún momento un estudio sobre las ideas políticas del movimiento almagrista, sin embargo, recogemos lo que al respecto apuntó Juan José Vega (1981):

Almagro tuvo a bien hacer públicas las razones de su alzamiento y anunció un plan de gobierno en servicio de todos los habitantes del Perú. Criticó severamente el mal gobierno que imperó bajo la égida de los Pizarro y tuvo severas frases de condenación para Valverde, el representante del poder religioso, por lo que hizo y por lo que no hizo ese obispo [...] No es el todo aventurado sospechar que el almagrismo insurgente pretendiese sinceramente la formación de una verdadera nación peruana, no sólo para beneficio de los conquistadores, sino también en defensa de la población nativa, porque sus postulados no estuvieron muy a la zaga que los 
lascasianos, y tal vez con una mejor dosis de pragmatismo (pp. 124-125).

El joven Almagro nombró tenientes en el Cuzco y Arequipa, y envió fuerzas a Trujillo por hombres, armas y caballos. Sin embargo, pronto surgió la reacción de los partidarios del difunto Marqués. Perálvarez Holguín en el Cuzco, Peranzúrez de Camporredondo en Charcas y Alonso de Alvarado en Chachapoyas, se negaron a acatar a Almagro, aduciendo que sólo reconocían la autoridad del Rey. Ello obligó al joven rebelde a sacar sus fuerzas de Lima hacia Jauja para cortar el avance de Perálvarez, pero este, reforzado por Peranzúrez, logró evadir el encuentro. Muerto Juan de Herrada por enfermedad, y en medio de disputas (que llegaron hasta al asesinato) entre sus oficiales, Almagro el Mozo logró llegar al Cuzco donde reorganizó sus tropas, se abasteció de armas y caballos, y ordenó la fundición de cañones a cargo del griego Pedro de Candía, uno de los "trece de la fama"; incluso contó con cierto respaldo de Manco Inca.

Estando Vaca de Castro en Popayán, se enteró del sangriento fin del Marqués y del alzamiento de Almagro. Conjeturó, y así afirmó en su carta al Emperador en noviembre de 1541, que los almagristas pensaban también asesinarlo por saber que no le quitaría el gobierno a Pizarro.

La situación en que se veía Vaca era crítica y excepcional: no conocía el país, le faltaban relaciones y apoyo, é ignoraba que influencia tendría la insurrección en la voluntad general. En tal conflicto se acreditó la firmeza de su carácter y la claridad de su juicio. Determinó esperar que los sucesos le guiasen, y seguir sin vacilar la senda que le marcaba el deber, y desoyendo los consejos de algunos que opinaban volverse a Panamá (Mendiburu, 1890, p. 178).

Aún convaleciente, el nuevo Gobernador marchó a Quito, acostado en unas andas y en compañía de un fraile franciscano con los Santos Óleos, por si la muerte le sorprendía en el camino (Jiménez de la Espada, 1877). El 26 de septiembre, ya en Quito, Vaca de Castro hizo pública la cédula que le daba la Gobernación en el caso de muerte de Pizarro, y envió copias de dicho texto a las ciudades más importantes del Perú a través de comisionados especiales. Mientras su salud mejoraba, Vaca de Castro reunía tropas y recursos para emprender la marcha contra Almagro, rechazando las propuestas del Adelantado Belalcázar en el sentido de negociar con el rebelde.

No seguiremos detalladamente las incidencias de la campaña. Sin embargo, apuntaremos que Vaca de Castro se irrogó el cargo de Capitán General, para evitar conflictos entre Perálvarez y Alvarado, a pesar de que su carrera era de letras y no de armas, falencia que se notó en algunos momentos de la campaña. El rebelde
Almagro envió cartas a Vaca de Castro manifestando su deseo de evitar la guerra, en base a su reconocimiento como Gobernador de Nueva Toledo, por herencia de su padre, pero conservando el Cuzco, pese al fallo del Emperador declarando que pertenecía a Nueva Castilla; la respuesta exigió la disolución del ejército almagrista y la entrega de los asesinos del Marqués. Como Vaca de Castro envió espías y agentes al campamento almagrista, ello se juzgó desleal llevando al fracaso de las negociaciones. Solo quedaba la solución de las armas.

Pocos días después, al atardecer del sábado 16 de septiembre de 1542, ambos ejércitos se encontraron en el campo de Chupas, cerca de Huamanga. Ambas fuerzas combinadas no llegaban ni a los 1500 hombres, pero aun así, se combatió con ferocidad. Al principio, la victoria se inclinó hacia los de Almagro, que contaban con una mayor cantidad de artillería, pero al final, la carga de la infantería encabezada por el sargento mayor Francisco de Carvajal, dio el triunfo a Vaca de Castro, el cual, combatió, lanza en ristre, casi al final de la jornada. Las minúsculas batallas de nuestro siglo XVI eran mucho más épicas que las gigantescas guerras de la Europa moderna; porque el predominio de las nobles armas blancas y de la caballería, y la misma pequeñez de los contingentes, daban a la lucha el carácter de la individualidad poética, que desaparece del todo en las confusas acciones contemporáneas. La exigüidad del número se rescataba con creces por lo reñido y mortífero de la pelea. En Chupas quedaron muertos o malheridos más de la mitad de los combatientes (Riva Agüero, 1995, pp. 109-110).

\section{VACA DE CASTRO, GOBERNADOR}

En el transcurso de la campaña, Vaca de Castro había difundido la noticia de su nombramiento como Gobernador. El Cabildo de Lima lo había reconocido el 20 de noviembre de 1541, a escondidas en el convento de Santo Domingo, perjudicando los planes de Almagro. Dicha proclamación se hizo luego de forma pública, cuando el Licenciado entró triunfalmente en Lima a mediados de 1542, en un breve viaje, antes de reunirse con su ejército concentrado en Jauja para marchar a la batalla final con los almagristas.

Habiendo derrotado a los almagristas, Vaca de Castro castigó a los rebeldes con suma dureza, sin mostrar clemencia alguna: a unos ajustició, a otros desterró. Luego, enterado de la prisión de Almagro el Mozo mientras intentaba refugiarse con Manco Inca, el Licenciado marchó hacia el Cuzco, donde entró con pompa excesiva (Cieza, 1994a). El proceso contra Almagro fue breve, apurado por sus intentos de soborno a los carceleros; condenado a muerte, se le negó la posibilidad de apelar al Rey o al Consejo de 
Panamá. Fue ejecutado a finales de noviembre de 1542, siendo enterrado junto a su padre en la Iglesia de la Merced del Cuzco. Con él, murió el bando de los de Chile.

Durante un lapso de poco más de un año, Vaca de Castro dirigió los destinos del Perú, entendiendo como tal al territorio de la Nueva Castilla y de la Nueva Toledo. La sede de su gobierno no fue Lima, sino la vieja capital incaica, el Cuzco. Para mantener el orden en Lima, Vaca de Castro envió al bachiller Juan Vélez de Guevara como teniente de gobernador, pero ni los oficiales reales ni los regidores se inclinaron por reconocerlo, quejosos de que el nombramiento se hubiese hecho en persona recién llegada al Perú. La situación llegó al extremo que de los cambios de palabra se pasó a los hechos, y quebraron la vara de Vélez de Guevara, y lo expulsaron de la sala del Cabildo. Temiendo la severidad del Gobernador, el contador Juan de Cáceres, el más furibundo de los que se opusieron a Vélez de Guevara, partió a Panamá, en tanto que los demás vivían bajo cuidado temiendo un castigo del ofendido Vaca de Castro (Herrera, 1615b). Lejos de ello, el Licenciado optó por disimular el desacato.

A diferencia del difunto Marqués Pizarro, que había obtenido el cargo de Gobernador por concesión de la Corona conforme con la Capitulación de Toledo de 1529, Vaca de Castro lo era por designación real, marcando así que el territorio peruano pasaría de un régimen contractual a uno sujetado plenamente a la Corona.

Vaca de Castro era, de hecho, un funcionario administrativo, cuyo nombramiento emana de la Corona, a propuesta del Consejo de Indias. Su periodo de mando era limitado y sus poderes eran delegados. Con ello se acentuaba el control de las autoridades metropolitanas sobre el país que hasta entonces había escapado a su competencia. Quedaba ahora el Perú integrado plenamente dentro del sistema de las jerarquías políticas y administrativas del complejo de la Monarquía española. Como ha dictaminado un especialista, "era el cambio de un sistema de ascendencia medieval por otro en el cual el Estado asume la plenitud de su Imperio" (Lohmann, 1994, p. 47).

¿Cómo fue el gobierno de Vaca de Castro? ¿Cómo cumplió los numerosos encargos que se le hizo en 1540 ? Las opiniones son diversas, pero mayormente coinciden en su capacidad de gestión: "no ovstante que Vaca de Castro partiçipó en los biçios de presunçion vana e vanagloria e codiçioso, sacado de estos viçios fue buen governador, e que hizo en el reyno buenas cosas" (Cieza, 1994a, p. 306); "demostró su competencia para el difícil cargo que se le había conferido" (Prescott, 1851, pp. 184-185); "aplicóse Vaca de Castro, con diligencia, sabiduría y acierto innegables á la gobernacion de aquel reino" (Jiménez de la Espada, 1877, p. 853); su "obra pacificadora [...] no se ha de desdeñar" (Vargas Ugarte, 1981, p. 175).

Un tema crucial era el de la delimitación de las gobernaciones de Nueva Castilla y Nueva Toledo. Vaca de Castro se encargó de tal tarea, y el 19 de septiembre de 1543 concluyó la demarcación: el Cuzco entraría dentro de la Nueva Castilla, en tanto que la Nueva Toledo comenzaría quince leguas al sur de la ciudad imperial, incluyendo en sus territorios a Arequipa, el Collao y Charcas. Vaca de Castro ordenó que los oficiales reales asignados a la Nueva Toledo, desempeñasen su labor desde Arequipa. Sin embargo, se hacía necesario unir ambas gobernaciones, y el Cabildo del Cuzco se hizo eco de esa idea en una carta al Emperador, del 20 de enero de 1543, sin enterarse aún que tal medida ya se había previsto en las llamadas Leyes Nuevas, dos meses antes. También pedían confirmar en el mando a Vaca de Castro, en lo que la Corona tuvo otros planes.

á cabsa de aver en estas partes divisas dos governaçiones, de Nueva Castilla y Nueva Toledo, ha sido cabsa y principal fundamental de los encuentros y vatallas pasadas é muertes de tantos cavalleros é hijosdalgo acaesçidas. é que nunca ha avido vn solo año de sosyego; de donde han proçedido notables dapnos é pérdidas á la hazienda Real de V.M. é sus súbditos que en ella residimos, y los yndios naturales están disipados y destruydos. Y pues esto está tan conosçido y entendido suplicamos á V.M. no permita que de aquí adelante haya divisyon en estas dos governaçiones [...] sea servido que la provisyon [como gobernador] hecha al dicho leçençiado Vaca de Castro no sea quitada ni admovida, antes de nuevo se la confirme, ansi de la Nueva Castilla como de la Nueva Toledo, pues todos estos reynos están todos generalmente contentos con su persona (Porras, 1959, pp. 532-533).

En cuanto a las finanzas de la Gobernación, Vaca de Castro debía inspeccionar el manejo de la real hacienda por los funcionarios responsables, los que en verdad, poco cuidado podían prestar en medio de las azarosas circunstancias que vivía el Perú. No obstante, el Gobernador estableció el servicio de la real hacienda, pudiendo remitir al Emperador un total de 354 mil ducados, y cuando arribó el Virrey, tenía reunidos 100 mil ducados más (Mendiburu, 1890).

Un asunto que amenazaría la precaria paz alcanzada era la masiva afluencia de soldados en el Perú. Vaca de Castro decidió enviar a los españoles ociosos en campañas de exploración de las comarcas que circundaban al antiguo territorio incaico (Juan Porcel a los Bracamoros, Diego de Rojas a Tucumán), o de reforzamiento de expediciones (Alonso de Monroy a Chile) o fundaciones en riesgo (Juan Pérez de Guevara a 
Moyobamba y Pedro de Puelles a Huánuco). Con ello, "remedianse los españoles que acá ay, y escusanse muchos inconvenientes y la vexaçion é daño que hazen á los naturals la mucha copia de gente" (Porras, 1959, p. 506).

\subsection{La protección del indígena}

Uno de los encargos cruciales de Vaca de Castro era el tema del cuidado de la población indígena. Intentó poner algún orden en los repartimientos, pero no pudo o no quiso definir el delicado asunto de la tasación de los tributos, cuyos exorbitantes montos constituían la principal carga de los indios. Otra medida fue el reservarse el comercio de la coca, a fin de evitar daño a la salud de los indígenas, y sin duda, también por las rentas que podía extraer de dicho rubro, las cuales utilizó para sus gastos y protocolo (Cieza, 1994a). No obstante, el Gobernador continuó con la tendencia legislativa en beneficio del indígena, ya iniciada por el difunto Marqués Pizarro.

Instituyó muy buenas ordenanças para la libertad de los Indios, y buena gouernacion, mediante las quales, fueron descargados de muchas estorsiones que auia permitido la licencia de la guerra. Quitó los holgazanes y valdios, y prohibio el ranchear, con lo gual se recogieron muchos Indios a poblar el Cuzco, y otros lugares, y se cultiuaron los campos, y aseguraron los caminos (Herrera, 1615b, p. 137).

\subsubsection{Las Ordenanzas de Minas}

El 13 de abril de 1543, desde el Cuzco, Vaca de Castro dictó las Ordenanzas de Minas. Dicho texto fue revisado en mayo y luego publicado el 21 de junio. Hemos revisado un resumen de dicha Ordenanza en la biografía que el padre agustino Casiano García Rodríguez dedicó al Gobernador leonés en 1957, texto elaborado en base a los documentos conservados en la Real Academia de la Historia.

Las Ordenanzas de Minas fueron un conjunto de medidas para conciliar el interés de la Corona en la producción minera y la legislación ya promulgada en el sentido de proteger a los indígenas. Así, se exigió que los indios expresasen libremente su voluntad de acudir a trabajar en las minas ante autoridad competente, y que debían ser bien tratados, fijándose el descanso dominical y en fiestas de guardar para su instrucción religiosa a cargo de un clérigo colocado para tal efecto en la iglesia que debía instalarse en cada centro minero. Adelantándose a las disposiciones de la mita dadas por el Virrey Toledo, se fijaron cuatro meses como tiempo de servicio de cada cuadrilla. Se estableció que los indígenas debían tener un alojamiento adecuado, y que su alimentación debía ser apropiada e incluyendo raciones de carne, maíz, sal, ají y coca. Los mineros debían contar en el campamento con lo que hoy llamaríamos insumos médicos. Se prohibió sacar indios de climas diferentes para el laboreo minero, a fin de evitar alejarlos demasiado de su lugar de origen. También se prohibió el castigo corporal indiscriminado y el uso de los indios como cargueros.

\subsubsection{Las Ordenanzas de Tambos}

E por saver el governador Vaca de Castro que en muchos de los aposentos o tanbos del camino real que va desde el Cuzco al Quito, que por no ser bien proveydos, se hazían grandes daños a los naturales, llevándolos en cadenas, (de que Dios nuestro Señor hera desservido, $e$ Su Magestad) hiço un probeimiento muy açertado e provechoso en aquel tienpo, e fue mandado a los comenderos e caçiques o señores de las provinçias que poblasen los tales aposentos segúnd e como estavan en tienpo del rey ynga Guayna Cápac, e que en ellos tuviesen vastimentos para los españoles que andubiesen por el reyno, e que fuesen obligados también, de tanbo a tanbo, de les dar çiertos yndios en que pudiesen llevar las cosas neçesarias, e sy algún español los pasase deste término que dezimos, que fuese castigado con reguridad. E desta manera los caminos estavan vien proveydos e los españoles pasavan por ellos syn trabajo (Cieza, 1994a, p. 316).

Al mes siguiente de las Ordenanzas de Minas, el 31 de mayo, se dio las Ordenanzas de Tambos, donde se reconocía el itinerario del antiguo Camino Inca desde Quito hasta La Plata y se ordenaba a los caciques locales proveer lo necesario para su buen mantenimiento. Los viajeros se proveerían de alimentos y cabalgaduras, además de un número fijo de indios de servicio, a los que podían utilizar hasta la próxima parada, guardando siempre el buen trato y justa paga de los indios que servían en dichos establecimientos.

La Ordenación hecha por Vaca de Castro pareciera haber tenido la intención de trasplantar la figura peninsular de los mesones y adaptarla a los tambos andinos. Los nuevos tambos se convirtieron en escalas de viaje y puntos de ruta de los intensos trajines del comercio interior. Con ello también se buscaba remediar los abusos que los españoles viajeros cometían contra los indígenas. Recientemente, el Ministerio de Cultura peruano (2018) ha hecho una nueva edición de las Ordenanzas de Tambos de Vaca de Castro, como una valiosa fuente para el conocimiento de la vialidad incaica y virreinal a través del camino inca.

\subsection{Asuntos eclesiásticos}

Una de las comisiones hechas a Vaca de Castro fue el tema de la delimitación de las jurisdicciones eclesiásticas. Hasta entonces, sólo existía un Obispado, el del Cuzco, creado en 1537. Así, el 18 de febrero de 
1543, se procedió a señalar los límites de los tres obispados. El obispado de Quito abarcaría las ciudades de Pasto, Popayán, Puerto Viejo y Santiago de Guayaquil con sus jurisdicciones y la isla de Puná. El obispado de Lima abarcaría las jurisdicciones de Trujillo, San Miguel de Piura, Huánuco y Moyobamba, hasta los límites con el obispado del Cuzco en el valle de Nazca. El obispado del Cuzco se quedaría con las jurisdicciones de Cuzco, Huamanga, Arequipa y el Collao hasta los límites con Chile.

El nuevo Obispo de Lima, fray Gerónimo de Loaysa, sobrino del Cardenal y ex Obispo de Cartagena, colaboró con Vaca de Castro por poco tiempo: recién arribó al Perú en marzo de 1543. Pero el mejor colaborador de Vaca de Castro fue el provincial de los domínicos, fray Tomás de San Martín, quien lo apoyó en la guerra contra Almagro; el provincial no supo o no pudo impedir los abusos del Gobernador, pero intentó frenarlos y mantenerlos secretos para evitar nuevas alteraciones (Berens, 2017). No es de sorprender la cercana relación del Licenciado con los frailes domínicos, la orden más fuerte en el Perú de entonces, recomendando al provincial como futuro obispo del Cuzco en reemplazo del difunto fray Vicente de Valverde, y favoreciendo la labor evangelizadora de la orden, con la creación de cuatro monasterios (en Chincha, en Huaylas, en Jauja y en Huamanga), como informó al Emperador en noviembre de 1542.

\subsection{Relaciones con Manco Inca y con los Pizarro}

Durante su labor de gobierno, y en cumplimiento de sus instrucciones, Vaca de Castro buscó aproximarse a Manco Inca para lograr su sumisión. En su carta del 24 de noviembre de 1542, el magistrado escribía al Emperador:

...los tratos que he escrito á V.M. que trayo con el Ynga, andan con mucho calor, avnque él me enbia papagayos é yo á él brocados: a me enviado en vezes dos capitanes de los prinçipales suyos, de tres que tiene, é las buenas respuestas que de mí han lleuado, y darle á entender como V.M. me dió sus prouisiones de seguro para él y perdón de sus cosas y delitos, é que V.M. manda que le dé uien de comer en la tierra y sea bien tratado (Porras, 1959, p. 504).

Pero pese a los acercamientos, no se logró ningún acuerdo. Manco Inca seguiría en pie de lucha contra la autoridad española; algunas fuentes hacen suponer la existencia de posibles negociaciones con el Virrey, que quedaron en nada por el asesinato del Inca a manos de españoles a los que había brindado refugio en Vilcabamba (Vega, 1981).

Durante su estancia en la Ciudad Imperial, Vaca de Castro procuró la cristianización definitiva de la elite inca leal al Rey, siendo un gran paso el bautismo del colaborador Paullu Inca con el nombre de Cristóbal, en honor a su padrino el Gobernador. Incluso, en base a un documento de 1608 firmado por un tal "fray Antonio", se afirma que Vaca de Castro ordenó realizar las primeras Informaciones sobre la sucesión de los incas; no obstante, afirma Porras (1963), "en los documentos contemporáneos a Vaca de Castro, en sus cartas e informes al Rey y en los de sus coetáneos, no ha quedado huella de hacerse realizado tales informaciones, de las que se tiene conocimiento tan sólo por este documento, y por una alusión, también tardía del Inca Garcilaso de la Vega" (p. 129).

Otro personaje con quien Vaca de Castro debió lidiar con sumo cuidado fue Gonzalo Pizarro, el último de los poderosos hermanos Pizarro que quedaba en el Perú. Enterado el Licenciado de que Gonzalo Pizarro se encontraba en Lima tras su frustrada expedición al País de la Canela, y ante los rumores sobre un eventual alzamiento, lo mandó llamar a Cuzco. Más rumores llegaron, en el sentido de que Gonzalo pretendía dar un golpe de mano y hasta asesinarlo, por lo que Vaca de Castro puso en alerta a sus tropas. A pesar de ello, el encuentro entre ambos fue cordial, logrando su propósito de alejar al altivo conquistador hacia su rica encomienda en los Charcas (Vargas Ugarte, 1981). Fue en tales circunstancias que el Gobernador envió a Vélez de Guevara como su teniente de gobernador en Lima. Aunque Gonzalo estuviese alejado de la luz pública, no por ello, Vaca de Castro dejó de estar pendiente de las reacciones del último de los hermanos Pizarro, en especial al hacerse públicas las Leyes Nuevas, tratando de frenar las voces que le alentaban a la rebelión contra la Corona (Cieza, 1994b).

Vaca de Castro también acogió a los menores hijos del Marqués Pizarro, Gonzalo y Francisca, pero dado que entre sus instrucciones figuraba el reducir la cantidad de indígenas en manos de la familia Pizarro, no dudó en usufructuar en beneficio propio, las rentas y tributos de varias encomiendas de los menores. Por ello, en octubre de 1544, ya con el Virrey al mando, Vaca de Castro se obligó al pago de 12,000 pesos de oro, aunque en el proceso que se entablaría luego en España, argumentó haber sido forzado a firmar (Varón, 1996).

\subsection{Las denuncias contra Vaca de Castro}

El gran vicio de Vaca de Castro, gracias al cual consideramos aceptó la misión al Perú, fue el ansia de dinero en aras de crear un linaje fuerte. Recordemos que era un hombre educado en los ideales medievales en medio del Renacimiento, considerando que el dinero era un medio para preservar y aumentar su estatus. Puesto a cargo de los destinos del Perú, el Licenciado no desaprovechó la oportunidad. 
Dotado de una amplia jurisdicción y excediendo sus atribuciones, el nuevo gobernador y presidente de la audiencia [de Panamá] tejió una rápida red recolectora de beneficios ajenos, despojando a los Pizarro, a Almagro El Mozo y a otras personas del producto de sus encomiendas y minas. Luego de emitir una "cédula de reformación" para las encomiendas de los Pizarro, que le sirviese de amparo legal, Vaca de Castro dio la "demasía", es decir, el excedente, a otros españoles, buscando afianzar un grupo que lo apoyase formado tanto por sus propios criados como por los colonos llegados con anterioridad (Varón, 1996, p. 141).

Otro cargo que se le hizo, fue el de vanidoso, y prueba hay para afirmarlo: Vaca de Castro incluso llegó a considerar, en carta a su esposa del 24 de noviembre de 1542, que el derrotar a Almagro había sido un servicio a la Corona superior al hecho por Pizarro con el descubrimiento y conquista del Perú:

Yo señora, he hecho á S. M. tan gran serviçio en ganarle estos reynos de tales tiranos y tantos y tan bien armados, encavalgados y artillados [...] Y pues al marques don Françisco Piçarro se tuvo por gran serviçio ganar estos reynos de indios, que fue fanarlos de ovejas, que por ello le dieron marquesado en ellos, y despues los perdió por su culpa y los gané yo de perdidos y de gente de nuestra nación (Porras, 1959, p. 511).

Esa célebre carta que Vaca de Castro envió a su esposa, interceptada por los enemigos del Licenciado, le causaría no pocos dolores de cabeza. Y es que en ese texto, el Gobernador recordaba las remesas de dinero y joyas que le había enviado, le recomendaba discreción en ocultar lo enviado, le aconsejaba utilizar personas de confianza para adquirir bienes rústicos o urbanos para no verse comprometido. Sólo a través del portador de esa carta en concreto, Vaca de Castro enviaba 5,500 castellanos de oro, esmeraldas y vajilla de plata.

En aras de acopiar dinero, Vaca de Castro se hizo de enemigos importantes en el Perú, que sumados a los que se hizo en la implacable represión de los almagristas, serían su desgracia. Uno de ellos, el contador Juan de Cáceres escribió al Emperador, desde Panamá en agosto de 1543, que desde que el Licenciado entró en el Perú, trató de ocultar que la Corona se enterase de los robos y cohechos que hacía en desmedro de la Real Hacienda. Cáceres criticó la conducta de Vaca de Castro en Chupas, su apropiación de la riqueza confiscada a los rebeldes derrotados, generando espanto en cómo fue nombrado un tan mal hombre, mentiroso, vanaglorioso, mal cristiano, codicioso, $i$ en quien concurren tantas $i$ tan malas calidades, que Dionisio Siracusano ni Sardanapalo en su tiempo no podían ser tan malos... metelle en su Consejo Real... i dalle el habito de Santiago y hacelle otras mil mercedes... Todos están a la mira a ver el castigo egemplar que V.M. mande hacer (Porras, 1959, pp. 548549).

Otros críticos eran personajes de alto nivel como el alcalde de primera nominación de Lima Francisco de Ampuero, el tesorero Alonso de Riquelme, el veedor García de Salcedo, el factor Illán Suárez de Carvajal, Nicolás de Ribera el Viejo y Diego de Agüero, quienes afirmaban la poca conveniencia de Vaca de Castro en el Perú, dado su interés en los repartimientos vacos y el orgullo con que desempeñaba sus funciones, suplicando se le tome residencia (Vargas Ugarte, 1981). Las denuncias contra el Licenciado habían llegado a tal nivel, que el Virrey Blasco Núñez, en viaje hacia el Perú, escribió al Emperador, desde Panamá en febrero de 1544, detallando incluso los nombres de los cómplices de Vaca de Castro, e incluso sugirió que "secretamente sin que fuese sabido de nadie antes ni después vuestra magestad mandase catar su casa porque si es verdad que a ynbiado la cantidad que dizen no podra dexar destar alli parte della" (Levillier, 1921, t. I, p. 90).

\subsection{Las leyes nuevas y la llegada del virrey}

En noviembre de 1542, el Emperador Carlos, ante las constantes críticas de fray Bartolomé de las Casas contra los abusos contra los indígenas, promulgó una serie de normas, conocidas como las Leyes Nuevas. Constaban de 39 normas, que reorganizaban el Consejo de Indias, creaban el Virreinato del Perú sobre la base de las antiguas gobernaciones de Nueva Castilla y Nueva Toledo, creaban dos nuevas Audiencias en Lima y en Guatemala, establecían reglas para el buen trato a los indígenas, y reformaban el sistema tributario. Las normas más conflictivas fueron las referidas a las encomiendas, cuya desaparición se preveía al morir el conquistador beneficiado, prohibiéndose además que fuesen encomenderos los funcionarios del gobierno, los religiosos, los que actuaban con negligencia o crueldad, y los que habían tomado parte en las luchas entre Pizarro y Almagro.

Las normas fueron conocidas en el Perú, inicialmente por extractos de las mismas, y luego por comunicaciones oficiales a Vaca de Castro, el cual, trató de serenar los ánimos de los irritados conquistadores y aconsejó el envío de una delegación ante el Emperador para explicar los argumentos de los encomenderos. Incluso algunos le ofrecieron rebelarse contra la Corona, a lo cual el Licenciado, enterado ya del viaje del nuevo Virrey, Blasco Núñez Vela, optó por marchar a Lima con tropas y artillería, lo que se prestó a suspicacias dada su mala relación con el Cabildo de Lima, el cual, hizo aprestos bélicos, por lo que el Gobernador debió dispersar sus tropas y dejar la artillería en Huamanga, lo que luego se lamentaría al caer en poder del rebelde Gonzalo Pizarro (Cieza, 
1994b). En Lima, ante las noticias sobre el carácter del Virrey, el alarmado Cabildo intentó que Vaca de Castro continuase en el mando, pero éste respondió que sería Gobernador hasta ver los títulos originales del Virrey. Ello se produjo el 15 de mayo de 1544, cuando Blasco Núñez efectuó su entrada solemne a Lima.

Pese a que el Virrey debía consultar los negocios de gobierno con Vaca de Castro, su desconfianza y antipatía le llevó a ordenar su prisión, primero en un cuarto del palacio virreinal a fines de mayo, y luego en junio, en un barco surto en la rada del Callao. Desde allí, Vaca de Castro se informó sobre la marcha de Gonzalo Pizarro hacia Lima, de los errores de Blasco Núñez, de su impopularidad y de su deposición por la Audiencia en septiembre de 1544, de la entrada triunfal de Gonzalo Pizarro en Lima y su nombramiento como gobernador en octubre de 1544. Convencido de que su presencia no servía ya en una tierra donde no tenía autoridad legítima y temiendo a los pizarristas, el Licenciado preparó su salida con la ayuda de su deudo García de Montalvo, quien logró sobornar al maestre de la nave y a varios marineros; en un momento de descuido, el navío zarpó hacia Panamá aprovechando que no había otra embarcación capaz de salir en su busca.

De Panamá, Vaca de Castro cruzó el istmo y viajó a las Azores, de donde pasó a Lisboa, y de allí a la Corte: había en Sevilla orden de prenderle y secuestrar sus bienes. Para cuando Vaca de Castro arribó a España en junio de 1545, su protector el cardenal Loaysa, había caído en desgracia luego de la visita al Consejo de Indias entre 1542 y 1543. Los almagristas en la Corte y los rivales que se había hecho durante su gestión, no dejaban de denunciar su conducta. Y Vaca de Castro terminó siendo encerrado en la fortaleza de Arévalo, luego en Simancas y finalmente a la villa de Pinto, sumando once años de prisión, aunque con las consideraciones debidas a su clase. En el proceso, el fiscal Juan de Villalobos lo acusó de veintiún cargos, entre los cuales, figuraban haberse apoderado de sumas pertenecientes a la Real Hacienda, y enviar dinero a España sin pasar por las aduanas, cargo confirmado por la carta enviada a su mujer, interceptada por el contador Cáceres. De dichos cargos, en 1545, fue absuelto de nueve, siendo condenado a fuertes multas por los otros doce (García, 1957).

En 1555, ya viudo, Vaca de Castro pidió la revisión de su caso ante el Consejo de Indias y el Consejo Real, logrando una sentencia absolutoria al año siguiente. Ello llevó a la restitución de su plaza en el Consejo Real, al pago de los salarios adeudados durante su prisión, y a la concesión de rentas en el Perú. El exgobernador desempeñó sus funciones hasta su retiro en 1564, tras lo cual, se retiró al convento de San Agustín en Valladolid, donde falleció en 1572.

\section{Apuntes finales}

Las principales crónicas sobre las Guerras Civiles en el Perú, se refieren indefectiblemente a la labor de Vaca de Castro; tanto Cieza de León, Gutiérrez de Santa Clara y Antonio de Herrera, como Fernández de Oviedo y Agustín de Zárate, o cronistas marginales como Pascual de Andagoya, Nicolao de Albenino y Alonso Borregán tienen en su mayoría, un juicio negativo del funcionario leonés. Fue a finales del siglo XVI, cuando se reivindicó la figura del Licenciado, debido al empeño de su hijo, el influyente Pedro de Castro y Quiñones [arzobispo de Granada, y luego de Sevilla], quien patrocinó los escritos áulicos de Juan Cristóbal Calvete de Estrella (Zapata, 2018).

Treinta años después de la batalla de Chupas, el Virrey Francisco de Toledo enjuiciaría a sus predecesores, afirmando que:

al remedio desto [los males de la guerra civil] vino vaca de castro que al prinçipio dio muestras de asentar la tierra y para ello hizo ordenanças las quales pareçieron bien a los de aquel tiempo por ser muchas dellas muy semejantes a las del ynga, como fueron las de las permisiones de serviçios y cargas de yndios pero en sabiendo la benida de blasco nuñez y los despachos que traya muchos días antes que llegase que eran a respecto de corregir las deshordenes pasadas y serviçios personales se començaron a hazer juntas en las cibdades para leer las copias de los dichos despachos por el poco secreto con que fue despachado no pareçio aver andado vaca de castro tan en benefiçio y asiento del reyno como hasta allí (Levillier, 1921, t. III, p. 305).

$Y$ es que la figura de Vaca de Castro no dejó de ser cuestionada tanto por contemporáneos como por los historiadores y estudiosos. Don Ricardo Palma le dedicó, en la segunda serie de sus Tradiciones Peruanas, un texto titulado Una carta de Indias, escrito con su particular gracejo, burlándose de la codicia y la vanidad del Licenciado leonés. El maestro Porras Barrenechea (1978), por su lado, consideró que Vaca de Castro "inspiró en algo a Cervantes para trazar la figura de Sancho Panza y hay risueñas analogías entre las cartas de Vaca de Castro a su mujer desde el Perú y las del escudero inmortal a doña Teresa Panza desde su ínsula momentánea" (p. 590). Creemos que es Varón (1996) quien acierta en sintetizar la gestión de Vaca de Castro, el último Gobernador de la Nueva Castilla:

En vista de su misión tan definida y los desastrosos resultados que ella generó, pocos gobernantes debieron defraudar tanto en su administración, aun en este período de formación colonial embrionaria, como Vaca de Castro. El funcionario prestó mayor atención a su propio beneficio que a la misión de gobierno que le 
había sido encomendada, desentendiéndose de las urgentes labores organizativas que se requerían ( $p$. 137).

\section{Bibliografía}

Berens, Loann (2017). Cristóbal Vaca de Castro y los domínicos del Perú. Revista de Estudios Latinoamericanos. Recuperado de https://www.academia.edu/36774454/Crist\%C3 \%B3bal Vaca de Castro y los dominicos del Per\%C3\%BA

Cieza de León, Pedro (1994a). Crónica del Perú. Cuarta Parte. Vol. II Guerra de Chupas. Lima, Perú: Pontificia Universidad Católica del Perú.

Cieza de León, Pedro (1994b). Crónica del Perú. Cuarta Parte. Vol. III Guerra de Quito. Tomo I. Lima, Perú: Pontificia Universidad Católica del Perú.

García, O.S.A., P. Casiano (1957). Vida de D. Cristóbal Vaca de Castro, Presidente y Gobernador del Perú. Madrid, España: Ediciones Religión y Cultura.

Herrera, Antonio de (1615a). Historia General de los hechos de los castellanos en las Islas y Tierra Firme del Mar Océano. Década Sesta. Recuperado de https://upload.wikimedia.org/wikipedia/commo ns/0/04/Antonio_de_Herrera_D\%C3\%A9cadas_ 5_y_6.pdf

Herrera, Antonio de (1615b). Historia General de los hechos de los castellanos en las Islas y Tierra Firme del Mar Océano. Década Sétima. Recuperado de https://upload.wikimedia.org/wikipedia/commo ns/9/9c/Antonio_de_Herrera_D\%C3\%A9cadas_ 7_y_8.pdf

Jiménez de la Espada, Marcos (1877). Datos biográficos. En Ministerio de Fomento de España. Cartas de Indias (pp. 701-871). Madrid, España: Imprenta de Manuel G. Hernández.

Levillier, Roberto (1921). Gobernantes del Perú. Cartas y papeles. Siglo XVI. Documentos del Archivo de Indias. Madrid, España: Sucesores de Rivadeneyra.

Lohmann Villena, Guillermo (1994). El gobierno y la administración. En Del Busto Duthurburu, José Antonio (Dir.). Historia General del Perú, Tomo V:
El Virreinato (pp. 18-25). Lima, Perú: Editorial Brasa.

Mendiburu, Manuel de (1890). Diccionario históricobiográfico del Perú. Tomo octavo. Lima, Perú: Imprenta Torres Aguirre.

Paniagua Pérez, Jesús (1988). Don Cristóbal Vaca de Castro, un leonés del siglo XVI en el Nuevo Mundo. Tierras de León. Recuperado de http://www.saber.es/web/biblioteca/libros/tierr as-de-leon/html/71/5cristobal.pdf

Porras Barrenechea, Raúl (1959). Cartas del Perú (15241543). Lima, Perú: Sociedad de Bibliófilos Peruanos.

Porras Barrenechea, Raúl (1963). Fuentes Históricas Peruanas (Apuntes de un curso universitario). Lima, Perú: Instituto Raúl Porras Barrenechea.

Porras Barrenechea, Raúl (1978). Pizarro. Lima, Perú: Editorial Pizarro.

Prescott, Guillermo H. (1851). Historia de la conquista del Perú con observaciones preliminares sobre la civilización de los Incas. Madrid, España: Imprenta y Librería de Gaspar Roig.

Riva-Agüero, José de la (1995). Paisajes Peruanos. Lima, Perú, Pontificia Universidad Católica del Perú.

Vaca de Castro, Cristóbal (2018). Ordenanzas de Tambos (Cuzco, 1543). Lima, Perú: Ministerio de Cultura.

Vargas Ugarte S.J., Rubén (1981). Historia General del Perú. El descubrimiento y la conquista (15241550), Lima, Perú: Editor Carlos Milla Bartres.

Varón Gabai, Rafael (1996). La ilusión del poder. Apogeo $y$ decadencia de los Pizarro en la conquista del Perú. Lima, Perú: Instituto de Estudios Peruanos - Instituto Francés de Estudios Andinos.

Varona García, María Antonia (1981). La chancillería de Valladolid en el reinado de los Reyes Católicos. Valladolid, España: Universidad de Valladolid.

- Vega, Juan José (1981). Historia General del Ejército, Tomo III: El ejército durante la dominación española en el Perú. Lima, Perú: Ministerio de Guerra.

Zapata Guzmán, Harley Antonio (2018). Cristóbal Vaca de Castro, Señor de Izagre y Santa María del Otero. En Real Academia de la Historia, Diccionario Biográfico electrónico. Recuperado de http://dbe.rah.es/biografias/4630/cristobalvaca-de-castro. 